\title{
Outbreak of ambler class A and D b-lactamase in multidrug-resistant Pseudomonas aeruginosa strains isolated from non burn patients
}

\author{
Zeynab Golshani ${ }^{1 \star}$, Ali Mohammad Ahadi $^{2}$ and Ali SHarifzadeh ${ }^{3}$ \\ ${ }^{1}$ Department of Microbiology, Young Researcher and Elites Club, Falavarjan Branch, Islamic Azad University, Isfahan, \\ Iran. \\ ${ }^{2}$ Department of Genetic, School of Science, Shahrekord University, Shahrekord, Iran. \\ ${ }^{3}$ Department of Microbiology, Shahrekord Branch, Islamic Azad University, Shahrekord, Iran.
}

Accepted 3 May, 2013

\begin{abstract}
Pseudomonas aeruginosa is a leading cause of infections including pneumonia, urinary tract infections and bacteremia, especially in patients with weakened immune systems. This pathogen is intrinsically resistant to many antibacterial agents, such as most beta lactams. The aim of this study was to survey antibiotic resistance pattern and frequency of bla VEB 1 and bla OXA10 genes in multidrug-resistance $\boldsymbol{P}$. aeruginosa isolated from non burn patients in Isfahan hospitals. Total of 100 clinical isolates of $\boldsymbol{P}$. aeruginosa from different samples were collected. Antibiotic susceptibility for antimicrobial agents was carried out according to the Clinical and Laboratory Standards Institute (CLSI) guidelines and the frequency of these genes was studied by polymerase chain reaction (PCR). Among the isolated strains, resistant rate to the antibiotic ciprofloxacin was $56 \%$, gentamicin $59 \%$, tobramycin $61 \%$, amikacin $65 \%$, imipenem $55 \%$, cefepime $55 \%$, ceftazidime $57 \%$, ceftriaxone $60 \%$, cefotaxime $62 \%$ and piperacillin was $48 \%$, respectively. $P$. aeruginosa demonstrated the highest resistance rate to amikacin (65\%), $55 \%$ of isolates were resistance to imipenem and cefepime whereas $63 \%$ were MDR (resistant to three or more classes of antibiotics). A multidrug-resistant (MDR) phenotype occurred frequently in $P$. aeruginosa. PCR was performed for all the resistant strains, prevalence of structural genes for VEB-1 and OXA-10 in isolates were $38(60 \%)$ and $40(64 \%)$, respectively. Proper infection control practices are essential to prevent spreading and outbreaks of ESBL-producing $P$. aeruginosa in hospitals.
\end{abstract}

Key words: Pseudomonas aeruginosa, ambler class A and D b-lactamase, antibiotic resistance.

\section{INTRODUCTION}

The blaVEB-1 and blaOXA10 extended spectrum $\beta$ lactamases (ESBLs)-genes belong to ambler class $A$ and $D$ and associated with multiple antibiotic resistances, in the form of a gene cassette. blaVEB was identified first in an Escherichia coli isolated from a child in France (Poirel et al., 1999). The blaVEB-1 gene is considered to be emerging, since its presence has been reported in many
Gram-negative organisms from different parts of the world during the last decade. It has been identified in Enterobacteriaceae and Pseudomonas aeruginosa in many countries, such as France, Spain, Algeria, Turkey, Canada, Korea and Thailand (Naas et al., 2008). The OXA-type enzymes are frequently observed in $P$. aeruginosa and possess high-level hydrolytic activity 
Table 1. Primer designed sets.

\begin{tabular}{llc}
\hline Primer & Sequence & Product size (bp) \\
\hline blaVEB1-F & 5'-GTGGAGTCCGATTAAAGAGG-3' \\
blaVEB1-R & 5'-CATCATTAGTGGCTGCTGC -3' & 449 \\
& & \\
blaOXA10-F & 5-ATTATCGGCCTAGAAACTGG-3 & 170 \\
blaOXA10-R & 5-CTTACTTCGCCAACTTCTCTG-3 & \\
\hline
\end{tabular}

against oxacillin and methicillin and their activities are poorly or not inhibited by clavulanic acid. These enzymes confer resistance to amoxicillin and cephalothin (Bush et al., 1995). Class D OXA-type b-lactamases, have extreme sequence variation, with the identities varying from 16 to $99 \%$ between individual enzymes. ESBLs are commonly encoded on plasmids that confer resistance to most cephalosporins, such as cefotaxime, ceftriaxone and ceftazidime (Nordmann and Guibert, 1998). Other ESBLs such as TEM and SHV types have been identified in the past (Bradford, 2001). TEM ESBLs are also extremely reported. These enzymes are constantly found in E. coli and Klebsiella pneumoniae and recently reported in $P$. aeruginosa at low frequency. These enzymes belong to the family of class A (TEM, SHV, CTX-M) betalactamase. Today, there are more than 157 TEM, 101 SHV, 65 CTX-M and 5 VEB variants (Poole, 2004). Antibiotic resistance in bacteria carrying these enzymes occurs in several ways, including efflux pumps, production of $\beta$-lactamases and outer membrane modifications (Zavascki et al., 2010). Many P. aeruginosa strains can produce several types of ESBLs that enable them to be resistant to many strong antibiotics (Jones, 2001). ESBLs are inactivated by the $\beta$-lactamases inhibitor (Drawz and Bonomo, 2010) for example clavulanic acid (Yu et al., 2006). So far, prevalence of blaVEB1 genes, in few studies have been shown. This study was performed to investigate the prevalence of Ambler class $A$ and $D$ b-lactamases in non burn isolates of $P$. aeruginosa.

\section{MATERIALS AND METHODS}

\section{Bacterial sources}

100 strains of $P$. aeruginosa were isolated from different infected patients in care unit of the hospitals (SHariati, Al Zahra, Imam Musa), in Isfahan within six months period (February to July 2012). Identification of the isolates was done according to standard microbiology tests including colonial morphology, oxidase positivity, the presence of characteristic pigments and growth at $42^{\circ} \mathrm{C}(\mathrm{Tam}$ et al., 2010).

\section{Antibiotic susceptibility tests}

Antimicrobial susceptibility test was performed for all isolates. Antibiotic disks included ciprofloxacin, gentamicin, tobramycin, amikacin, imipenem, cefepime, ceftazidime, ceftriaxone, piperacillin and cefotaxim. A sterile loop was used to pick colonies of $P$. aeruginosa, then emulsified in $5 \mathrm{ml}$ of sterile Mueller Hinton broth to match with $0.5 \mathrm{McF}$ arland $\left(1.5 \times 10^{8} \mathrm{cfu} / \mathrm{ml}\right)$. A sterile swab using, the surface of Mueller Hinton Agar (Oxoid, Basingstoke, UK) in a Petri dish was evenly inoculated with the suspension and then the disks were put. The plate was then incubated at $37^{\circ} \mathrm{C}$ for $18 \mathrm{~h}$. The diameters of the zones of inhibition were measured in millimetres. Disks (Himedia, Mumbai) were used. P. aeruginosa ATCC 1310 was used as quality control strain in susceptibility determination. Multidrug-resistant (MDR) isolates were defined as those showing resistance to three or more classes of antipseudomonal agents (carbapenems, fluoroquinolones, penicillins/cephalosporins and aminoglycosides) (Jarlier et al., 1998).

\section{DNA extraction}

DNA extracted with phenol/chloroform briefly, $1 \mathrm{ml}$ of $24 \mathrm{~h}$ grown $P$. aeruginosa in Brain-Heart Infusion Broth (BHI) (Scharlau, Spain) were transferred into $1.5 \mathrm{ml}$ sterile microfuge tubes and centrifuged at $13.000 \mathrm{~g}$ for $10 \mathrm{~min}$. The pellets were dissolved in $500 \mu \mathrm{l}$ of lysis buffer ( $\mathrm{NaCl} 1 \mathrm{M}$, Tris-HCl $100 \mathrm{mM}$, EDTA $0.5 \mathrm{M}), 20 \mu \mathrm{SDS}(10 \%)$, $3 \mu \mathrm{l}$ of proteinase $-\mathrm{K}(20 \mathrm{mg} / \mathrm{ml})$ and incubated at $55^{\circ} \mathrm{C}$ for $2 \mathrm{~h}$. Then, phenol/chloroform/isoamylalchol (25:24:1 volume/volume) were added, vortexed, and centrifuged at $12.000 \mathrm{~g}$ for $10 \mathrm{~min}$. The supernatants were transferred to sterile tubes. $1 \mathrm{ml}$ of $95 \%$ cold ethanol was added and stood for $1 \mathrm{~h}$ in refrigeration condition $\left(4^{\circ} \mathrm{C}\right)$. DNA was then precipitated in each tube by centrifugation at 12.000 $\mathrm{g}$ for $10 \mathrm{~min}$. The precipitated DNA was dissolved in $50 \mu \mathrm{l}$ of $10 \mathrm{mM}$ Tris EDTA - buffer (TE) (Shacheraghi et al., 2010).

\section{PCR reaction}

PCR was used to detect blaVEB1 and OXA10 genes, in the multidrug resistant bacterial strains using the following primer designed sets (Table 1).

Total volume of reaction was $25 \mu \mathrm{l}$. PCR Master consisted of $1 \mathrm{X}$ PCR reaction buffer (Sinaclon), $\mathrm{MgCl}_{2}$ 0/7 $\left.\mu \mathrm{l}\right)$, dNTP $(0 / 5 \mu \mathrm{l}), 1 \mu \mathrm{l}$ of each primer, $10 \mathrm{mM}$ Tris- $\mathrm{HCl}$, Taq DNA polymerase $(0 / 2 \mu \mathrm{l})$ and $1 \mu \mathrm{l}$ of DNA template. Amplification was carried out in a thermocycler (Eppendorf Mastercycler®, USA). Agarose gel electrophoresis $(1 \%)$ of PCR products was carried out in horizontal bed apparatus using $1 \mathrm{mM}$ Tris-Borate- EDTA (TBE) buffer $(\mathrm{pH}-7)$ at $85 \mathrm{~V}$ for $1 \mathrm{~h}$ and the bands were then stained with $0.5 \mu \mathrm{g} / \mathrm{ml}$ ethidum bromide for $10 \mathrm{~min}$. The reaction conditions were as follows: pre-denaturation at $94^{\circ} \mathrm{C}$ for $4 \mathrm{~min}$, followed by 25 amplification cycles of $94^{\circ} \mathrm{C}$ for $1 \mathrm{~min}, 55^{\circ} \mathrm{C}$ for $1 \mathrm{~min}$ and $72^{\circ} \mathrm{C}$ for $1.5 \mathrm{~min}$, with a final extension step of $72^{\circ} \mathrm{C}$ for $10 \mathrm{~min}$. The gels were washed and observed under U.V. gel documentation (UV DOC, England) at $280 \mathrm{~nm}$. $100 \mathrm{bp}$ DNA ladder was used to confirm the size of specific bla gene. Simultaneously, a positive control was run for bla genes $(P$. aeruginosa strains containing blaVEB-1 and bla OXA-10 were prepared from stock collection of Institute pasture of Iran). P. aeruginosa PTCC 1074 was used as a sensitive strain (negative control) (Shacheraghi et al., 2010). 


\begin{abstract}
TTCGCGCGGCCCGGAACCCGATGGGACGGTATAGCCCCAGTGCCATGAGCAATGGGTAAGTGACTTGACCTTCAG TGGGGCAATACAAGTTTCAGCTGTTCCCGTATTTCAACAAATCGCCAGTGAAGTTGGCCGAAGTAAGTTATAACACC TTCTTTTTCCCCTTCTTTCTTTCTCTTCTCCCTTCTCCTGACTTCTCCTTTCCATCCCCTCTCTCCTCCCTGGTTTCCC CTTCTTCCTTTACCTCCTTCTCTCCGCCCCCCCCCCCAGCCACCTCCCCTCTGCTACCTCGCCTTCCTTCCGTCTCC

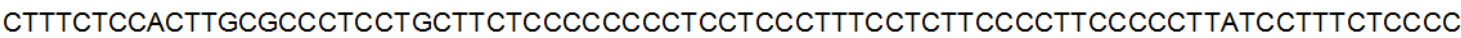
GCTTCTGTCCTTACCCCTGCTCCTTCCTTTCCTGCTGTCCCCCGCTCCGCCCCCCCCTTCGTCTCTTCTCCCTCCTC CCCTTTTCGCGCTCCTCTCCTTCTTCCTCTATCTCCCGTTGCTCTCCGTCGTGTTCTGTTCTCCCTCTTCTCTTCCTG CTTCCGTCTCCCTTTTCGTCTTTGTTCCGTTCTCTTTCTCTCTTTCCTTCGTTTTGCCACTTCATGCCTCCTATCACCC TTGTTTTCCСССTCTTTCTCTCCTTTCTTCTCСTCCСССTTTCTCCCTCTTTTTTTCTTGC
\end{abstract}

Figure 1. Sequences of blaoxa-10 of $P$. aeruginosa strains isolated from patients in Isfahan hospital. The nucleotide sequences was analyzed with CROMASPRO-2 and MEGA 4 software and confirmed by blast system in the internet.

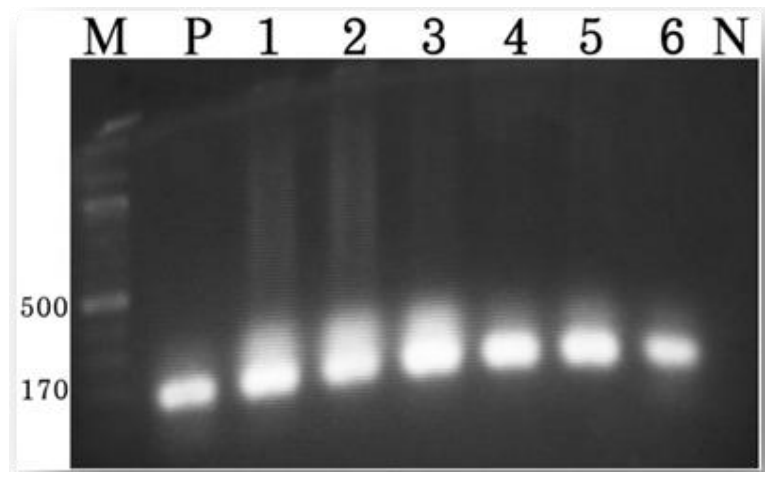

Figure 2. Agarose gel electrophoresis of PCR product of class $D$ betalactamase blaOXA-10 detected from $P$. aeruginosa isolates. $\mathrm{M}=$ Molecular weight marker (100$\mathrm{bp}), \mathrm{P}=$ positive control, 1,3 to $6=$ strains producing OXA10 genes (170 bp), $\mathrm{N}=$ negative control.

\section{Sequencing of the PCR products}

DNA sequencing was subjected to direct sequencing of both the strands performed by the Macrogen Company (Seoul, Korea) (Al Naiemi et al., 2006). The nucleotide sequences were analyzed with CROMASPRO-2 and MEGA-4 softwares (Figure 1).

\section{Statistical analysis}

SPSS version 11.5 was used to analyze the data, and a Fisher exact test was used for the categorical data. P-value of $\leq 0.05$ was considered significant.

\section{RESULTS AND DISCUSSION}

The prevalence of multidrug-resistant $P$. aeruginosa producing ESBLs is increasing worldwide (Bonomo and Szabo, 2006). Antibiotic resistance that can be related to plasmid or chromosome occur in $P$. aeruginosa isolated from patients in different hospitals in Iran (Shakibaie, 2002). Our results reported the highest resistance rate to amikacin and cefotaxime, with $65,62 \%$ and lowest resistance rate to piperacillin, imipenem and cefepime with 48 and $55 \%$, respectively. In our study, amikacin resistance value was higher than values reported in study conducted by Amutha et al. (2009). In the study of Prashant et al. (2011), highest resistance rate to ceftazidime $(53 \%)$ and lowest resistance rate to imipenem (12\%) was reported. In the present study, resistance to gentamicin: $59 \%$, tobramycin: $61 \%$, ceftazidime: $57 \%$, ceftriaxone: $60 \%$ and cefotaxime: $62 \%$, was observed, also PCR was performed for all the resistant strains, the frequency of bla VEB1 gene was 38 $(60 \%)$ and blaOXA10 gene was $40(64 \%)$ among 63 strain with multidrug resistance (Figure 2), that have significant increase as compared to the previous studies.

In Saudi Arabia, Tawfik et al. (2012) reported that resistance rate to ceftazidime piperacillin, piperacillin/tazobactam, cefepime, aztreonam, imipenem, amikacin, gentamicin and ciprofloxacin were 22.43, 100, $71.14,88.57,48.57,70.0,82.5,87.5$ and $90.0 \%$, respectively. The prevalence of ESBL and $\mathrm{MBL}$ in $P$. aeruginosa was 69.44 and $42.85 \%$, respectively. Also, prevalence of structural genes for VEB-1, OXA-10 and GES ESBLs in isolates was 68, 56 and $20 \%$, respectively. VIM gene was detected in $15(100 \%)$ of 
MBL-producing isolates. As can be seen, the frequency of this genes in Iran and Saudi Arabia, are almost identical to each other. While, in the case of antibiotic resistance, there is a significant difference. Mirsalehian et al. (2010) in Tehran (Iran) showed that, aztreonam, Imipenem and meropenem were the most effective antipseudomonal agents. Also, they reported that 148 $(87.05 \%)$ of the isolates were MDR and $67(39.41 \%)$ of the isolates were ESBL producer. Fifty $(74.62 \%), 33$ $(49.25 \%)$ and 21 (31.34\%) strains among 67 ESBLproducing strains amplified blaOXA-10, blaPER-1 and blaVEB-1, respectively. There was significant differences between the results of the present study and that of Mirsalehian et al. (2010), which may be due to differences in the specimens type (burn and non burn). Class D OXA $\beta$-lactamases were more frequently detected than class $A$ in $P$. aeruginosa from Korea $(21.0$ versus $6.3 \%$ ), which contrasts with data from Europe (31.3 versus $64.9 \%$ ) and our study (60 versus $64 \%$ ). In the study of Lee et al. (2005) in Korea, among the 252 isolates, $53(21.0 \%)$ isolates harboured OXA-type enzyme. Among them, blaOXA-10, like our study, was most prevalent, and OXA-4, OXA-2, OXA-30 and OXA-17 also had a high frequency. 6 isolates $(2.4 \%)$ harboured two different $\beta$-lactamases and one isolates harboured three enzymes. PER-1, VEB-1, TEM, SHV, CTX-M and GES-1 enzymes were not detected. Bert et al. (2002) reported that four isolates of $P$. aeruginosa produced ESBLs according to the double disc synergy (DDST) (phenotypic) method. PCR showed that 68 (26.3\%) isolates was carrier of OXA-10 group includeing: 31

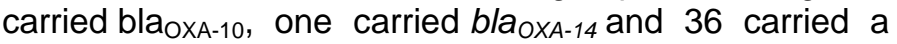
new variant between bla $a_{O X-13}$ and bla OXA-19. The bla OXA2 gene was identified in $13(5 \%)$ isolates. According to the results, we can say that the prevalence of these genes was much lower in 2002. The most prevalent betalactamase genes were blaVIM-2 and blaOXA-10 in the study of Suk et al. (2007). Lee et al. (2005) found that in $64(25.4 \%)$ isolates, there was prevalence of OXA-10 (13.1\%), OXA-4 (4.3\%), OXA-30 (2.0\%), OXA-2 (2.3\%) and OXA-17 (0.4\%); their distribution varied between provinces. The cross-class resistance rates to other antibiotics was significantly higher in class $A$ and $D \beta$ lactamase producers than in non-producers. Suk et al. (2007) reported that $2.9 \%$ of isolates were multidrugresistant (MDR), PCR amplification, and sequencing of the PCR products showed that the blaOXA-10, blaVIM-2, blaOXA-2, blaOXA-17, blaPER-1, blaSHV-12, and blalMP-1 genes were carried by 34.3, 26.9, 3.0, 3.0, 1.5, 1.5 and $1.5 \%$ of 67 MDR $P$. aeruginosa isolates, respectively. As compared to our study, the frequency is less. Prevalence of blaOXA10 and VEB1 in the study of Shacheraghi et al. (2010) in Tehran was 92\%, in burn patients. Finally, the prevalence of MDR $P$. aeruginosa encoding blaOxa10 In Iran (64 to 92\%) was higher, when compared with that from Korea (13\%), France (26\%) and india. Although, the prevalence of this genes in Tehran
$(92 \%)$, is higher than that in our study, probably it is due to the high prevalence of these resistant genes in burn patients.

\section{ACKNOWLEDGEMENTS}

We thank members of Islamic Azad University, Falavarjan Branch and also Dr. momtaz for helpful suggestion. This work was supported by the Islamic Azad University, Falavarjan Branch, Iran.

\section{REFERENCES}

Al Naiemi N, Duim B, Bart AA (2006). CTX-M extended-spectrum Blactamase in Pseudomonas aeruginosa and Stenotrophomonas maltophilia. J. Med. Microbiol. 55:1607-1608.

Amutha Padmakrishnan R, Murugan T, Renuga devi MP (2009). Studies on multidrug resistant Pseudomonas aeruginosa from pediatric population with special reference to extended spectrum beta lactamase. Indian. J. Sci. Technol. 11-13.

Bert F, Catherine B, Nicole LZ (2002). Identification of PSE and OXA $\beta$ lactamase genes in Pseudomonas aeruginosa using PCR-restriction fragment length polymorphism. J. Antimicrob. Chemother. 1:11-8.

Bonomo RA, Szabo D (2006). Mechanisms of multidrug resistance in Acinetobacter species and Pseudomonas aeruginosa. Clin. Infect. Dis. Bush K, Jacoby GA, Medeiros AA (1995). A functional classification scheme for $\beta$-lactamases and its correlation with molecular structure. Antimicrob. Agents. Chemother. 39(43):S49-56.

Bradford PA (2001). Extended-spectrum $\beta$-lactamases in the $21 \mathrm{st}$ century: characterization, epidemiology, and detection of this important resistance threat. Clin. Microbiol. Rev. 48:933-51.

Drawz SM, Bonomo RA (2010). Three Decades of $\beta$-Lactamase Inhibitors. Clin. Microbiol. Rev. 23:160-201.

Jarlier V, Nicolas MH, Fourneir G (1998). Extended spectrum $\beta$ lactamases conferring transferable resistance to newer $\beta$-lactam agents in Enterobacteriaceae: Hospital prevalence and susceptibility patterns. Rev. Infect. Dis.10:867-78.

Jones RN (2001). Resistance patterns among nosocomial pathogens: trends over the past few years. Chest 2:397-404.

Lee s, Park YJ, Kim M, Lee HK, Han K, Kang CHS, Kang MW (2005). Prevalence of Ambler class $A$ and $D$ B-lactamases among clinical isolates of Pseudomonas aeruginosa in Korea. J. Antimicrob. Chemother. 56:7-122.

Mirsalehian A, Feizabadi M, Nakhjavani FA, Jabalameli F, Goli H, Kalantari $N$ (2010). Detection of VEB-1, OXA-10 and PER-1 genotypes in extended-spectrum beta-lactamase-producing Pseudomonas aeruginosa strains isolated from burn patients. Burns 36(1):70-4.

Naas T, Poirel L, Nordmann P (2008). Minor extended-spectrum $\beta$ lactamases. Clin. Microbiol. Infect. 14(Suppl. 1):42-52.

Nordmann P, Guibert M (1998). Extended-spectrum beta-lactamases in Pseudomonas aeruginosa. J. Antimicrob. Chemother. 42:128-131.

Poirel L, Naas Th, Guibert M, Chaibi EB, Labia R, Nordmann P (1999). Molecular and biochemical characterization of VEB-1, a novel class $A$ extended-spectrum beta-lactamase encoded by an Escherichia coli integron gene. Antimicrob. Agents. Chemother. 43:573-581.

Poole K (2004). Resistance to $\beta$-lactam Antibiotics. Cell. Mol. Life Sci. 61:2200-2223.

Prashant DP, Basavaraj VP (2011). ESBL and MBL Mediated Resistance in Pseudomonas aeruginosa: An Emerging Threat to Clinical Therapeutics. J. Clin. Diag. Res. 8:1552-1554.

Shacheraghi F, Shakibaie M, Noveiri H (2010). Molecular Identification of ESBL Genes blaGES-1, blaVEB-1, blaCTX-M blaOXA-1, blaOXA4, blaOXA-10 and blaPER-1 in Pseudomonas aeruginosa Strains Isolated from Burn Patients by PCR, RFLP and Sequencing Technology. Int. J. Bio. Sci. 6:3.

Shakibaie MR (2002). Plasmid mediated metal and antibiotic resistance 
in Pseudomonas aeruginosa strains isolated from burn patients. Med. J. Islam. Republic Iran 16:159-163.

Suk SE, Yoo JS, Lee JK, Lee KM, Chung GT, Shin ES, Han SY, Lee $\mathrm{SH}$, Kim J, Lee YS (2007). Investigation of beta-lactamase-producing multidrug-resistant Pseudomonas aeruginosa isolated from nontertiary care hospitals in Korea. J. Microbiol. Biotechnol. 10:1733-7.

Tam VH, Chang KT, Abdelraouf K, Brioso CG, Ameka M, McCaskey LA, Weston JS, Caeiro JP, Garey KW (2010). Prevalence, resistance mechanisms, and susceptibility of multidrug-resistant bloodstream isolates of Pseudomonas aeruginosa. Antimicrob. Agents Chemother. 3:1160-64.
Tawfik AF, Shibl AM, Aljohi MA, Altammami MA, Al-Agamy MH (2012). Distribution of Ambler class $A, B$ and $D$-lactamases among Pseudomonas aeruginosa isolates. Burns 38(6):855-60.

Yu WL, Chuang YC, Rasmussen JW (2006). Extendedspectrum betalactamases in Taiwan: epidemiology, detection, treatment and infection control. J. Microbiol. Immunol. Infect. 39:264-77.

Zavascki AP, Carvalhaes CG, Picão RC, Gales AC (2010). Multidrugresistant Pseudomonas aeruginosa and Acinetobacter baumannii: resistance mechanisms and implications for therapy. Expert Rev. Anti. Infect. Ther. 1:71-93. 